\title{
Investigation of Grain Boundary Compositions and Magnetic Properties of Hot-Worked $\mathrm{Nd}_{18} \mathrm{~Tb}_{1} \mathrm{Fe}_{66.5} \mathrm{Co}_{5} \mathrm{Al}_{1.5} \mathrm{~B}_{8}$ Magnets
}

\author{
G. SadullahoĞLu ${ }^{a}$, B. Altuncevahir ${ }^{b}$ And A. Okan AdDemir ${ }^{a}$ \\ ${ }^{a}$ Istanbul Technical University, Metallurgical and Materials Engineering, 34469, Maslak, Istanbul, Turkey \\ ${ }^{b}$ Istanbul Technical University, Physics Engineering, 34469 Maslak, Istanbul, Turkey

\begin{abstract}
Magnetic properties which are related to the compositions on the grain boundaries of the NdFeB permanent magnets were studied at different hot working temperatures applied to the cast $\mathrm{Nd}_{18} \mathrm{~Tb}_{1} \mathrm{Fe}_{66.5} \mathrm{Co}_{5} \mathrm{Al}_{1.5} \mathrm{~B}_{8}$ ingots. Since the addition of $\mathrm{Al}$ caused the formation of hard magnetic $\mu$ phase between the magnetic NdFeB crystals after the pressing $800^{\circ} \mathrm{C} H_{\mathrm{c}}$ value increased to the highest value of $8.21 \mathrm{kOe}$. According to the SEM micrographs and EDS analysis, the increase in pressing temperature, the atomic ratios in the $\mathrm{NdFeAl}$ compositions approached to hard magnetic $\mu$ phase with the increase in pressing temperature and its exact composition was obtained in the sample hot deformed at $800^{\circ} \mathrm{C}$. Although the secondary $\mu$ phase with a high melting temperature is detremental to the alignment of $c$ axis of the magnetic NdFeB grains along the pressing direction, we found that the magnetic properties of the magnets improve due to the presence of this hard magnetic phase on the grain boundaries.
\end{abstract}

DOI: 10.12693/APhysPolA.123.233

PACS: $75.50 . \mathrm{Ww}, 75.50 . \mathrm{Vv}, 75.50 . \mathrm{Bb}$

\section{Introduction}

Hot deformation of cast alloys is an alternative method for sintered high performance $\mathrm{RE}-\mathrm{Fe}-\mathrm{B}$ magnets. Magnetic alignment of the hard $\mathrm{Nd}_{2} \mathrm{Fe}_{14} \mathrm{~B}$ phase is achiEved by hot pressing, upset forging, hot rolling or extrusion [1-4]. The addition of $\mathrm{Al}$ to $\mathrm{NdFeB}$ magnets enhanced strongly $H_{\mathrm{c}}$ due to the increased liquid state wettability during sintering heat treatment and the formation of new phases stabilized by $\mathrm{Al}$. In $\mathrm{Fe}-\mathrm{Nd}-\mathrm{Al}$ ternary system, several binary or ternary phases are in equilibrIum. Both $\delta\left(\mathrm{Nd}_{33} \mathrm{Fe}_{70-x} \mathrm{Al}_{x} ; 7<x<25\right)$ and $\mu\left(\mathrm{Nd}_{33} \mathrm{Fe}_{67-x} \mathrm{Al}_{x}\right.$; $2.5<x<5)$ phases are stable on the $\mathrm{Al}$ poor part of the $\mathrm{Nd}-\mathrm{Fe}-\mathrm{Al}$ system and are observed in $\mathrm{Fe}-\mathrm{Nd}-\mathrm{B}-\mathrm{Al}$ magnets [5-8]. In this study, we investigated the hot working temperature on the microstructure and magnetic properties of the $\mathrm{Al}$ doped $\mathrm{NdFeB}$ cast alloys.

\section{Experimental}

The alloy composition of $\mathrm{Nd}_{18} \mathrm{~Tb}_{1} \mathrm{Fe}_{68.5} \mathrm{Co}_{5} \mathrm{~B}_{8} \mathrm{Al}_{1.5}$ was prepared by induction melting in a quartz tube under vacuum about $10^{-3}$ mbar and solidified in water to achieve fine microstructure. Hot deformed magnets were produced by hot-pressing of the as-cast ingots in an open die at 710,750 and $800^{\circ} \mathrm{C}$ under high purity argon atmosphere. The pressure during the hot pressing was 2.55 ton $/ \mathrm{cm}^{2}$. Hot pressed samples were heat treated at $580^{\circ} \mathrm{C}$ for $1 \mathrm{~h}$. Scanning electron microscope (SEM) equipped by an energy dispersive spectrometer (EDS) was utilisied to investigate microstructure of the specimens. $2 \times 2 \times 2 \mathrm{~mm}^{3}$ specimens were cut from the hot pressed magnets. Magnetic measurements of the cubic samples were performed under a maximum magnetizing field of $20 \mathrm{kOe}$ with a vibrating sample magnetometer (VSM). Thermal differential analyzing (DTA) was used to define phase transformations.

\section{Results and discussions}

The SEM micrographs of the as-cast ingot and hot pressed cast alloys at 710,750 and $800{ }^{\circ} \mathrm{C}$ are shown in Fig. 1. The microstructure of the cast ingot consists mainly of two phases; $\mathrm{Nd}_{2} \mathrm{Fe}_{14} \mathrm{~B}$ ferromagnetic matrix phase (region (a)) and Nd-rich intergranular phase (region (b)). In Fig. 1a and $b$, the magnetic grains are isotropic and columnar shaped and no free iron was detected in the cast ingots in EDS analysis. According to the EDS results small part of $\mathrm{Al}$ entered the magnetic $\mathrm{Nd}_{2} \mathrm{Fe}_{14} \mathrm{~B}$ structure, the rest of $\mathrm{Al}$ remained in the intergranular region.

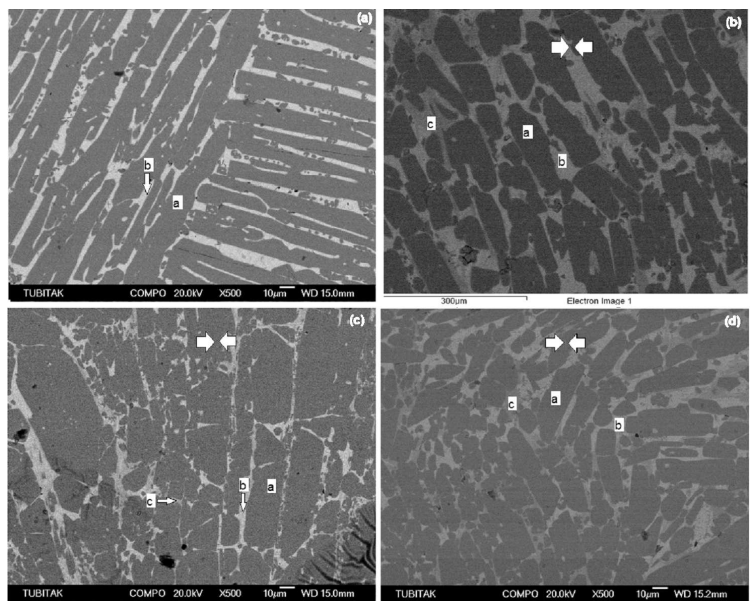

Fig. 1. SEM images of the samples as cast (a), hot pressed at $710^{\circ} \mathrm{C}$ (b), $750{ }^{\circ} \mathrm{C}$ (c), and $800{ }^{\circ} \mathrm{C}$ (d) $a$ : $\mathrm{Nd}_{2} \mathrm{Fe}_{14} \mathrm{~B}, b$ : Nd-rich phase and $c$ : FeNdAl composition. Arrows show pressing directions.

The intergranular regions were separated into two compositions after hot pressing process consisting of Nd-rich (a) and $\mathrm{NdFeAl}$ ternary composition (c). 
TABLE

Atomic percents of the elements in region $c$ in the hot pressed samples.

\begin{tabular}{c|c|c|c|c|c}
\hline \hline \multirow{2}{*}{$\begin{array}{c}\text { Pressing } \\
\text { temp. }\left[{ }^{\circ} \mathrm{C}\right]\end{array}$} & \multicolumn{5}{|c}{ Atomic percent [\%] } \\
\cline { 2 - 6 } & Fe & Nd & Co & $\mathrm{Al}$ & $\mathrm{O}$ \\
\hline 710 & 40.25 & 44.29 & 4.33 & 3.71 & 7.41 \\
750 & 45.38 & 39.72 & 5.24 & 3.98 & 5.68 \\
800 & 59.33 & 30.72 & - & 3.94 & 6.02
\end{tabular}

According to Table the amount of $\mathrm{Nd}$ in the $\mathrm{NdFeAl}$ phase decreased when the deformation temperature increased from $710^{\circ} \mathrm{C}$ to $800^{\circ} \mathrm{C}$ and the composition of $\mu$ phase was observed in the microstructure of the sample hot pressed at $800{ }^{\circ} \mathrm{C} . \mu$ phase $\left(\mathrm{Nd}_{33} \mathrm{Fe}_{67-x} \mathrm{Al}_{x}\right.$ $2.5<x<5)$ is hard ferromagnetic with a high anisotropy field $\left(\mu_{0} H_{\mathrm{A}}>8 \mathrm{~T}\right)$ and formed by peritectic reactions at about $750^{\circ} \mathrm{C}[8]$. The surface oxidation most probably occurred during preparation process of the samples for SEM analysis.

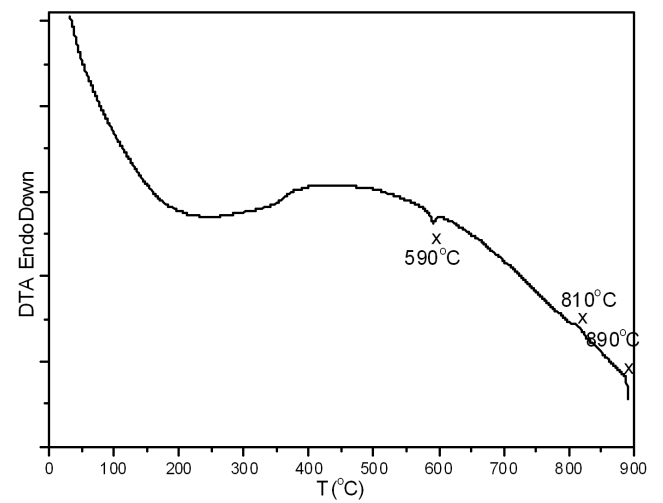

Fig. 2. DTA thermograph of the sample hot pressed at $800{ }^{\circ} \mathrm{C}$.

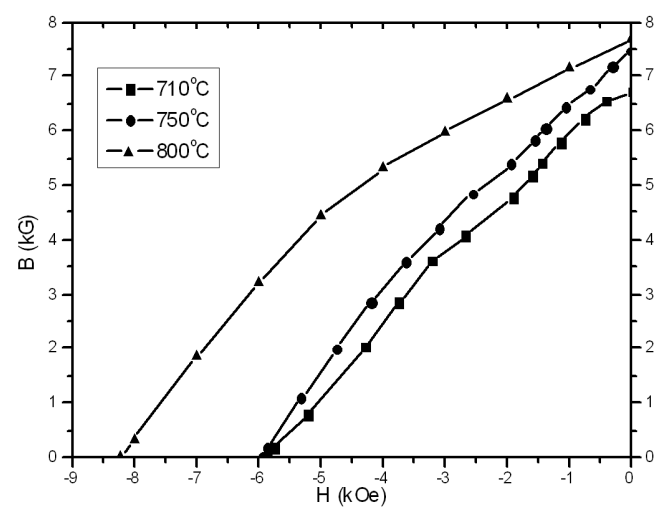

Fig. 3. Demagnetization curves of the samples hot pressed at different temperatures.

In the thermal analysis of the sample hot pressed at $800^{\circ} \mathrm{C}$ (Fig. 2) the endothermic reaction occurred at about $590^{\circ} \mathrm{C}$ which corresponds to melting temperature of Nd-rich phase in the intergranular region. The other exothermic and endothermic reactions observed at about $810^{\circ} \mathrm{C}$ and $890^{\circ} \mathrm{C}$ are attributed to $L+\delta+\psi \leftrightarrow \delta+\psi_{2}$ and $\delta+\psi_{2} \leftrightarrow L+\psi_{1}+\delta$ transformations, respectively, because $\mu$ phase disappears and those two reactions occur at $805^{\circ} \mathrm{C}$ and $900{ }^{\circ} \mathrm{C}$, respectively $\left(\delta=\mathrm{Nd}_{30} \mathrm{Fe}_{62-x} \mathrm{Al}_{8+x}\right.$ is tetragonal and antiferromagnetic, $\psi, \psi_{1}$ and $\psi_{2}$ phases are $\mathrm{Nd}_{2}(\mathrm{Fe}+\mathrm{Al})_{17}$ where $\mathrm{Al}$ and $\mathrm{Fe}$ ratios change).

Figure 3 indicates the demagnetization curves of the samples hot pressed at 710,750 , and $800^{\circ} \mathrm{C}$ and annealed at $580^{\circ} \mathrm{C}$ for $1 \mathrm{~h}$. According to the demagnetization curves, the sample hot deformed at $800^{\circ} \mathrm{C}$ has the highest $B_{r}$ and $H_{\mathrm{c}}$ values which can be attributed to the formation of $\mu$ phase on the grain boundaries because it is a hard ferromagnetic and has large anisotropy field $\left(H_{\mathrm{A}}\right)$ which increase the coercivity significantly. $B_{r}$ and $H_{\mathrm{c}}$ values increased to $7.67 \mathrm{kG}$ and $8.21 \mathrm{kOe}$, respectively.

\section{Conclusions}

In this study, we obtained the highest $B_{r}$ and $H_{\mathrm{c}}$ values for the sample hot deformed at $800^{\circ} \mathrm{C}$ due to the presence of hard ferromagnetic $\mu$ phase on the grain boundaries. In the microstructures of the pressed samples the grain alignment is not good, because the high melting $\mathrm{NdFeAl}$ composition inhibits the grain rotation during hot pressing process. The improvement of the magnetic properties are most probably due to the hard magnetic properties of $\mu$ phase. In the microstructure of the cast alloy the intergranular region composes of only Nd-rich phase. After hot working process $\mathrm{NdFeAl} \mathrm{ternary} \mathrm{compo-}$ sitions were observed in all samples. With the increase in pressing temperature, atomic ratios in the $\mathrm{NdFeAl} \mathrm{com-}$ positions approached hard magnetic $\mu$ phase and its exact composition was obtained in the sample hot deformed at $800^{\circ} \mathrm{C}$. The improvement of the magnetic properties of the hot pressed samples by the increase in deformation temperature might be attributed to the enhancement of the amount of $\mu$ phase in the microstructure by increasing pressing temperature.

\section{References}

[1] J.P. Nozieres, R. Perrier de la Bathie, J. Magn. Magn. Mater. 80, 88 (1989)

[2] V. Sinka, T. Kvackaj, O.B.G. Assis, M. Ferrante, J. Alloys Comp. 230, 42 (1995).

[3] T. Shimoda, K. Akioka, O. Kobayashi, T. Yamagami, T. Ohki, M. Miyagawa, T. Yuri, IEEE Trans. Magn. 25, 4099 (1989).

[4] K. Akioka, T. Yamagami, T. Shimoda, J. Appl. Phys. 69, 5829 (1991).

[5] J.P. Nozieres, R. Perrier de la Bathie, IEEE Trans. Magn. 25, 4117 (1989)

[6] B. Grieb, E.-Th. Henig, G. Martinek, H.H. Stadelmaier, G. Petzow, IEEE Trans. Magn. 26, 1367 (1990).

[7] L. Legras, J. Delamera, D. Lemarchand, J. Vu Dinh, P. Vigier, J. Alloys Comp. 218, 17 (1995).

[8] B. Grieb, E.-T. Henig Z. Metallkde. 82, 560 (1991) 